\title{
The Utilization Of Internet Of Things For Multi Sensor Data Acquisition Using Thingspeak
}

\author{
Mohamad Jamil ${ }^{1}$, Muh.Ridwan Lessy ${ }^{2}$, Sumiyati Samuda ${ }^{3}$ \\ \{jamil@unkhair.ac.id¹,mrlessy@unkhair.ac.id², sumisamuda@unkhair.ac.id $\left.{ }^{3}\right\}$ \\ Informatics Engineering, Faculty of Engineering \\ Khairun University, Ternate 97719, Indonesia ${ }^{13}$, Marine Science Faculty Of Fishers and Marine \\ Science, Khairun University, Ternate 97719, Indonesia ${ }^{2}$
}

\begin{abstract}
Internet Of Things (IoT) is one form of innovation that aims to expand the benefits of continuously connected internet connectivity, one example of the use of this technology is in terms of remote monitoring (eg remote monitoring); monitoring weather conditions, water levels, air pollution, forest fires and so on. In this research will apply the utilization of Internet Of Things (IoT) for acquisition of multisensor measurement data using the Thingspeak interface. Based on the results of tests conducted it was found that various series of sensors, such as; temperature sensors, water level sensors, vibration sensors and smoke sensors can display data in the form of results graphs through the Thingspeak software.
\end{abstract}

Keywords: internet of things, acquisition, multisensor, temperature, water level, vibration, GAS, thingspeak.

\section{Introduction}

Today, the development of information technology and telecommunications, especially data communication has experienced a fairly rapid development, one of the most prominent example of Internet technology. In accessing the today internet, it can be done in various ways, both using wired technology or wireless. In line with this, then the current use and utilization of the internet is not only used for surfing in the virtual world (browsing) but in line with this innovation of the Internet has been developed together with sensor technology, through the integration of information technology and electronics is then emerged a technology known as name of Internet Of Things (IoT).

IoT is an internet network that provides, processes and transfers digital in-formation obtained from sensor equipment such as radio frequency identification (RFID), infrared sensor, GPS, scanner and smart meter [1]

According to Hidayatullah, (2017) the Internet of Thing (IoT) is a method that aims to maximize the benefits of internet connectivity to transfer and process data or information via an internet network wirelessly, virtual and autonomous.[2],[3] One example of the use of this technology is in terms of remote monitoring (remote monitoring) eg; monitoring weather conditions, water levels, air pollution, forest fires and so on. The technologies in IoT are connected with various data collecting terminals through internet network and other communication networks. Information about the environment around the object is retrieved in real time, then converted into the appropriate data format to be transmitted over the network, ICCSET 2018, October 25-26, Kudus, Indonesia

Copyright (C) 2018 EAI

DOI 10.4108/eai.24-10-2018.2280578 
and sent to the data center. The data is then processed by an intelligent processor by using cloud computing and other smart computing technologies that can process large amounts of data, to achieve IoT objectives [4],[5].

In the process of collecting data between nodes that exist in a network required an interface that serves as a data collector that collects data from node devices and also allows data to be retrieved into the software environment for historical data analysis using an IoT platform that is Thingspeak.

ThingSpeak is an opensource "Internet of Things" application and API for storing and retrieving data from things that use HTTP over the Internet or through a Local Area Network [6], [7]

Based on the above explanation, the purpose of this research is to reveal how to utilize Internet Of Things (IoT) technology to get the measured data of various types of sensors (multisensors) that are visualized in a web-based interface using Thingspeak.

\section{Method}

\subsection{Type of Research}

The research type was Experimental and bibliography. Place of Research was at Computer Laboratory Faculty of Engineering Khairun University. In addition, to complement the supporting data of research was also done by looking for references from the books and sources derived from journals on the internet, so it can support research and applied to systems designed

\subsection{Techniques of Data Collection}

The process of collecting data or called preprocessing phase, is the initial phase done in this research to identify, evaluate and analyze cases and problems that happened done with two approaches:

1. Literature study: It is a search and literacy stages from various sources, both printed and electronic, such as textbooks and journals related to the research

2. System Analysis: It is a stage that aims to analyze the problems obtained from the identification. In this stage it is also the determining to be able to continue to the next stage

\subsection{Stages of Design (Phase Designer and Fabrication)}

There were several design stages used in the realization of this system are:

1. Preprocessing Phase: An initial stage that aims to track references related to the research being made. This phase consists of literature studies and system analysis.

2. Phase Designer and Fabrication: It is a design stage, and the proposed system is created. This stage consists of the design of hardware (hardware) and design software (Software) 
3. Phase Testing: Is the final phase of several phases / stages that have been made. In this phase will be a process of testing the system created before the implementation.

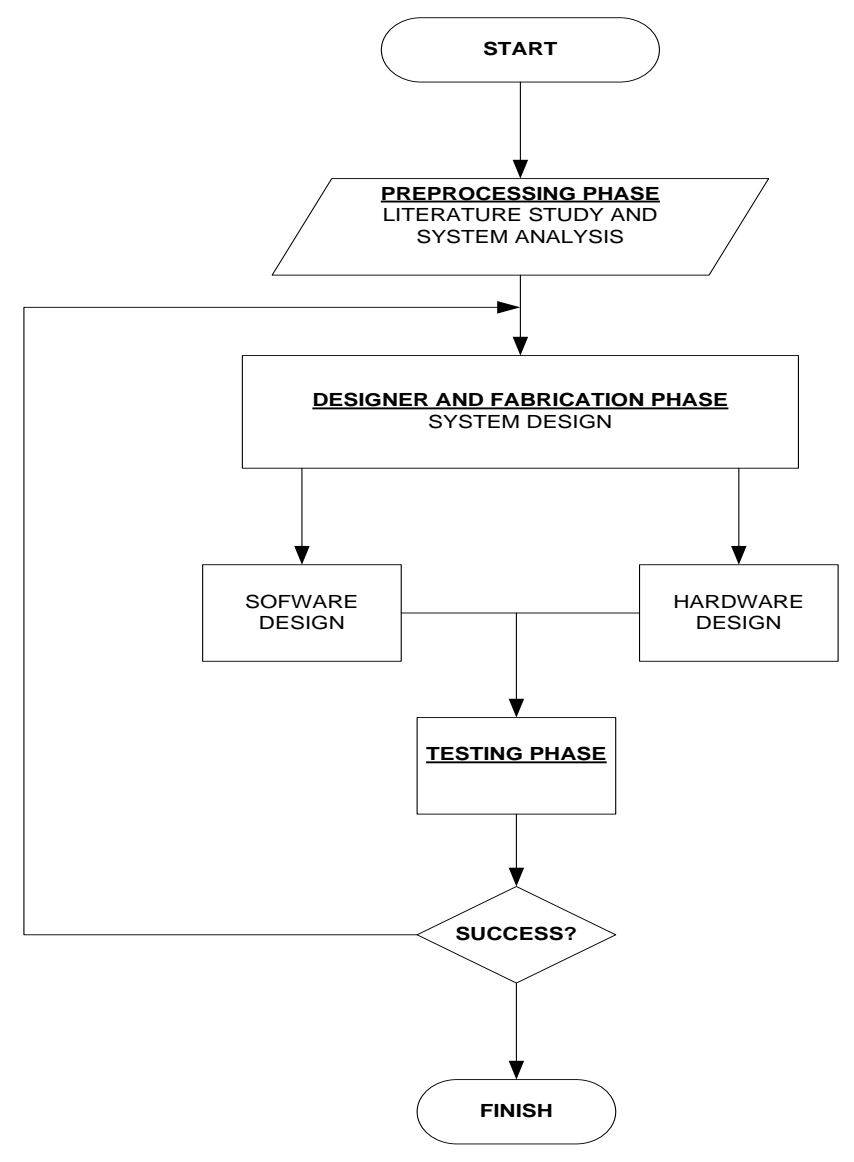

Fig. 1. Flow Chart of Research Method.

\section{Finding and Discussion}

\subsection{System Planning}

Stages of system planning in this study begins from the design of hardware and then proceed with the design of software tools. In the design stage of hardware begins with the system block diagram planning. Figure 2 describes the block diagram of the planned system 


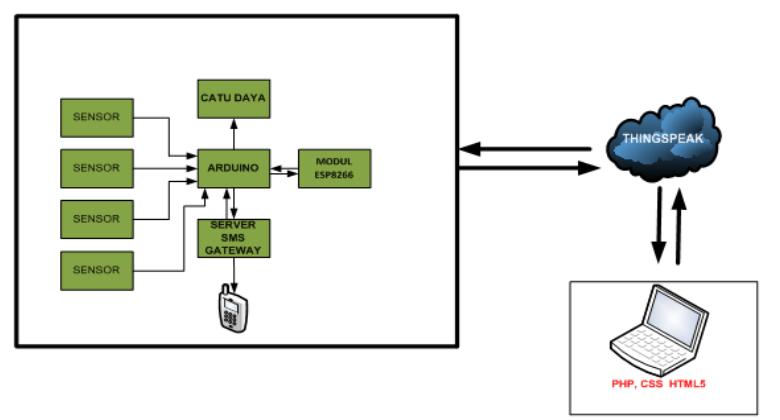

Fig. 2. Diagram Block.

From the block diagram illustrated can be explained how the workings of the system planned are as follows:

a. Sensors generally serve to detect any physical or chemical environment changes and can be used to convert a certain quantity into analog units so that it can be read by an electronic circuit in this study. Sensors used are Water level sensors, Vibration Sensors, Smoke Sensors, and Temperature sensor

b. The sensor circuit is then conveyed to an arbitial Input/Output (I / O) port for processing and processing

c. Data processed by arduino will then be displayed via Personal computer and via serial communication using ESP 8266 module and arduino GSM module (SMS GATEWAY).

d. To display the data received then the user can use cloud platform software one of them Thingspeak, through this application then the user can monitor the various changes received by the sensor circuit

The following will be discussed design of several series of sensors:

1. Temperature Sensor Module Series

The design of temperature sensors used in this study is LM35. Pin Out from LM35 will connect to Port A5 arduino. Figure 3 Showing LM35 sensor design and linkage to arduino

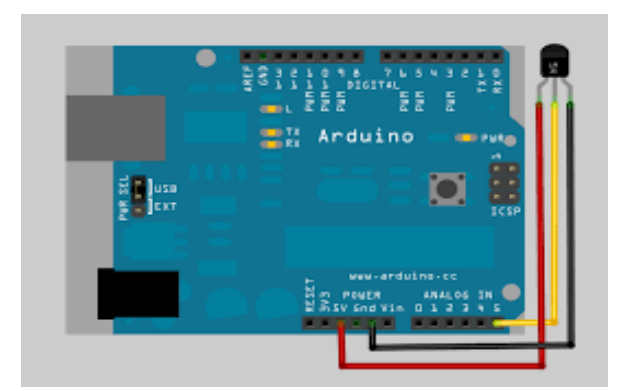

Fig. 3. Design of LM35 Sensor Module. 


\section{Water Level Sensor Module Series}

In this research, the water level sensor design used is water level sensor. Figure 4 shows the water level sensor design with arduino.

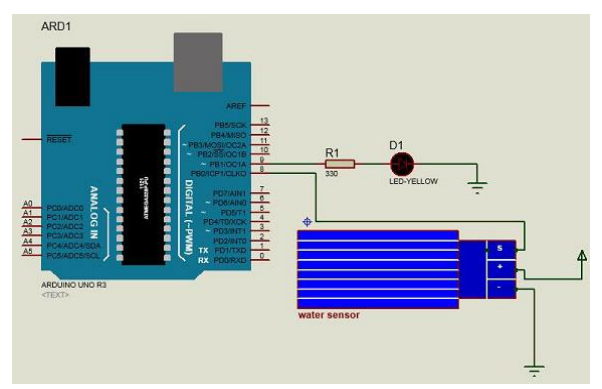

Fig. 4. Design of Water Level Sensor Module.

3. Vibration Sensor Module Series

In this research the vibration sensor design uses vibration sensor. For the Output pin of the vibrating sensor will be connected to port D0 Arduino. Figure 5 shows a vibration sensor design with an arduino

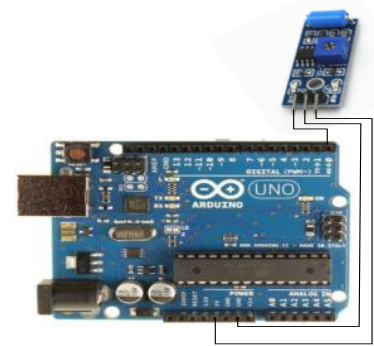

Fig. 5. Design of Vibration Sensor Module.

4. Smoke Sensor Module Series

In this study the design of smoke sensor using GAS sensor. To pin Output from vibrating sensor will be connected to port D3

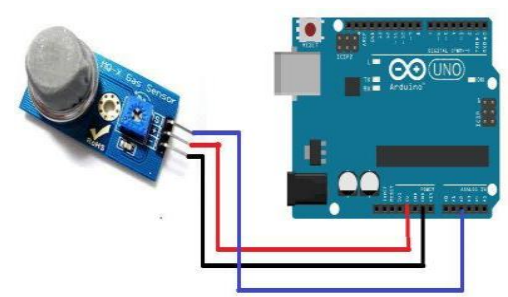

Fig. 6. Design of Smoke Sensor Module. 


\subsection{System Testing}

Hardware testing aims to determine the capabilities of each device and components used in response to data received. Subsequently, the constraints generated will be analized to overcome the problems that arise.The process of testing is done by connecting hardware with Thingspeak software. The following will be shown test results from various sensor circuits
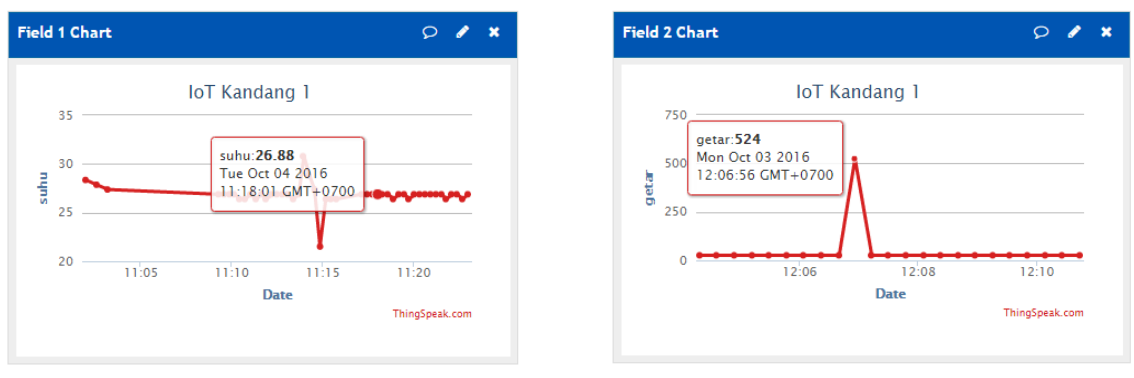

Fig. 7. Temperature Sensor and Vibration Sensor Tests Data.
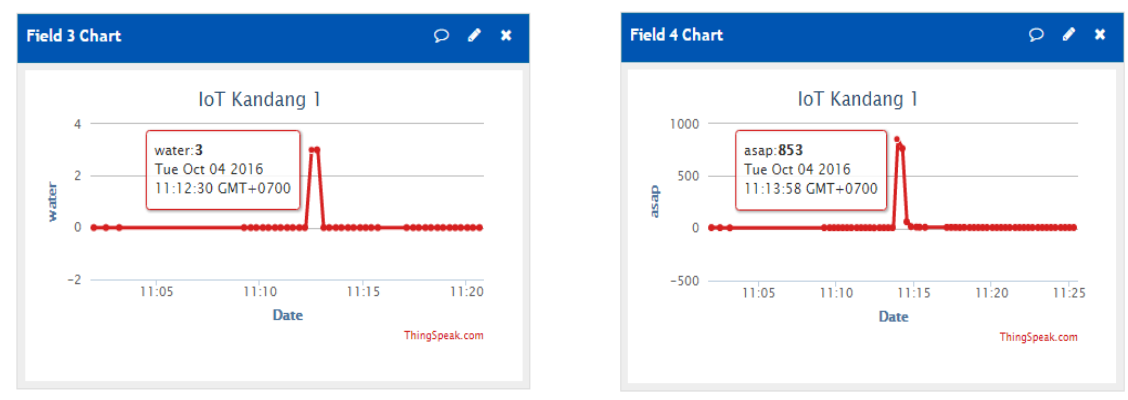

Fig. 8. Water sensor and Smoke Sensor level testing data.

\section{Conclusion}

Based on the results of tests conducted, it is revealed that the technology of the Internet Of Things (IoT) can visualize data of multisensor measurement results using applications of Thingspeak

\section{References}

[1] J. Momoh, "Smart grid design for efficient and flexible power networks operation and control," Power Syst. Conf. Expo. IEEE/PES, pp. 1-8, 2009.

[2] N. A. Hidayatullah, "Design and Application Internet Of Things (IoT) For Smart Grid Power System," J. Volt. 2017, 2017.

[3] M. Jamil and S. Samuda, "THE UTILIZATION OF INTERNET OF THINGS FOR MULTI 
SENSOR DATA ACQUISITION USING," no. 2017.

[4] L. Y. Qiang, G. Quan, B. Yu, "Research on SecurityIssues of the Internet of Things.pdf," Int. J. Futur. Gener. Commun. Netw., vol. 6, pp. 1-10, 2013.

[5] J. L. Roman, J. Zhou, "On the Features and Challenges of Security and Privacy in Distributed Internet of Things," Comput. Netw. Journal, Elsevier, 2013.

[6] M. G. and S. B. Sharifnejad, M. Shari, "A Survey on Wireless Sensor Networks Security," SETIT, 2007.

[7] S. Ulan, Purnama, "Platform Thingspeak," Univ. Sriwij., 2016. 